\title{
Evaluation of some properties of heat curing denture base materials cured by different curing techniques
}

Accepted: 9/ 10/ 2016

\begin{abstract}
Background and objective: Dry pressure curing device is one of the devices used in curing of acrylic resin denture bases. This study aimed to evaluate some properties of acrylic resins, cured by three different techniques.

Methods: Two hundred and fifty two specimens were prepared from two brands of heat curing acrylic resin (Paladent20 and Major). The specimens were cured by three techniques (dry heat pressure curing, conventional curing and microwave irradiation). For each curing technique, seven specimens were prepared and some mechanical and physical properties were tested.
\end{abstract}

Results: Less residual monomer showed in the dry heat pressure curing of Paladent 20 acrylic resin. The conventional curing of Major acrylic resin has shown the least porosity. The highest bending strength and less water sorption showed by microwave irradiation of Major acrylic resin specimens.

Conclusion: Some properties of the specimens cured by the dry heat pressure curing device were better than other curing techniques. The microwave irradiation has some good properties when compared with other techniques. The Paladent 20 brand of acrylic resin showed better properties than the Major acrylic resin.

Keywords: Dry pressure curing device; Denture base materials; Curing techniques; Properties

\section{Introduction}

The most commonly used denture base resin is Polymethyl methacrylate (PMMA), different mechanisms are used for its polymerization process. ${ }^{1}$ PMMA was used since the 1930s; it is characterized by easy handling, reduced cost, and satisfactory clinical outcomes. ${ }^{2}$ They composed of polymer and monomer; they mixed together, the mixture needs curing, which may be self-curing or may be heat curing. ${ }^{3}$ The conventional polymerization cycle is a long, low-temperature water-bath polymerization where the acrylic resin is processed at $74^{\circ} \mathrm{C}$ for 9 hours. ${ }^{4}$ There are also post polymerization cycles such as terminal boiling at $100^{\circ} \mathrm{C}$ for durations of 30 minutes (short-term) or longer than 1 hour (long-term). ${ }^{5}$ Microwave heating is independent of thermal conductivity. A cleaner method of processing, less cumbersome equipment and reduced curing time are advantages of curing denture base resin by microwave energy. 6,7 The final product of this technique has the same quality of physical properties, and a better accuracy of fit, resulting in improvement denture base adaptation. ${ }^{5,8}$ Heat cured denture base material exhibited higher tensile strength as compared to self-cure denture base material. ${ }^{9}$ Acrylic resin cured by microwave showed the highest mean transverse strength, while the lowest mean showed by visible light cured acrylic resin. Slightly lower transverse strength values calculated in heat cured resins had than microwave-cured resin. ${ }^{10}$ Porosity may be due to many factors such as the presence of residual monomer, air entrapment during mixing, monomer contraction during the polymerization, monomer vaporization

* Department of Prosthodontics, College of Dentistry, Hawler Medical University, Erbil, I raq. 
associated with exothermic reaction ${ }^{5}$. It have been concluded that the mean percent porosity was related to the specimens' weights and the absolute density of acrylic resin. ${ }^{11}$ The amount of water sorption on the surface and into the body of the material represents sorption of a material. The presence of deeper porosity and surface flaws may be the cause of water sorption in acrylic resin. ${ }^{12}$ Incomplete conversion of monomers into the polymer is known as residual monomer, which causes inflammation, irritation, and an allergic response of the oral mucosa. ${ }^{15}$ The mechanical properties level of residual monomer are closely related to the polymerization conditions. ${ }^{16}$ When terminal boils was used in polymerization cycles the levels of residual monomer were markedly decreased. ${ }^{17}$ Nowadays, many types of equipment developed for simplifying the curing procedure and to produce better properties for the cured acrylic resin. One of these new types of equipment is dry heat pressure curing unit. This study aimed to select the most suitable curing cycle of a new curing technique (dry heat pressure curing device) for heat curing acrylic denture base resin and evaluate the effect of dry heat pressure curing on the properties of ( transverse strength, porosity test, water sorption, water solubility and residual monomer release) of cured denture base material in comparison to the conventional and microwave irradiation curing techniques of two brands (Paladent 20 and major) heat cured acrylic resin.

\section{Methods}

Two hundred fifty two specimens prepared
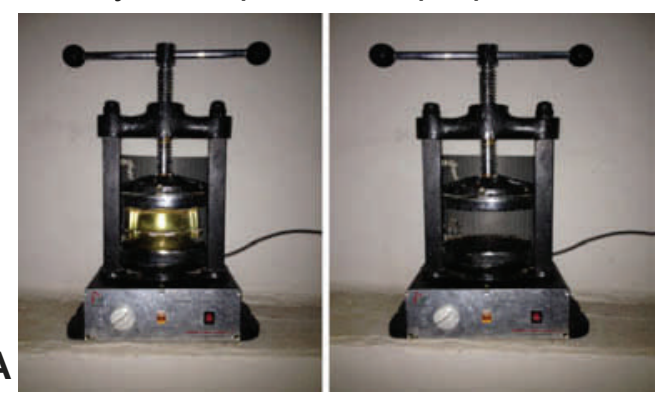

from two brands of Heat curing acrylic resin: the first 126 specimens made from the brand (Paladent ${ }^{\circledR} 20$ ) (HerausKulzer $\mathrm{GMBH}$ ) while the other 126 specimens made from the brand (Major) (Major. Base20, Major ProdottiDentariS.p.A.). The specimens evaluated for changes in bending, porosity, water sorption, water solubility and residual monomer tests.

\section{Dry pressure curing unit:}

Dry pressure curing unit (Guangzhou Lingchen Trading Co. Ltd, China) is one of the new devices; used for the processing of heat curing acrylic resin by dry curing and under permanent constant pressure. It is a manual press used in packing of heat curing acrylic resin into flasks. During packing, the pressure will be applied manually to press the lower half of the flask into position. It has two thick plates one below and the other above the flask, the flask will be pressed between them and the flask maintain in position for curing acrylic resin. The metal plates contain electrical heaters, the heat transmitted through the direct contact between the plates and the body of the flask. The device has an on-off switch bottom and an automatic timer, Figure (1.A).

Microwave flask:

A special type of the flask was used in this study. It was a triangle-shaped fiberglass flask, has three screws for tightening the parts of the flask together. The flask have upper and lower metal parts used during pressing the flask by the hydraulic press to avoid its fracture. It is removed from the flask when placed in the microwave oven to prevent reflection of the wave inside it, Figure (1.B)

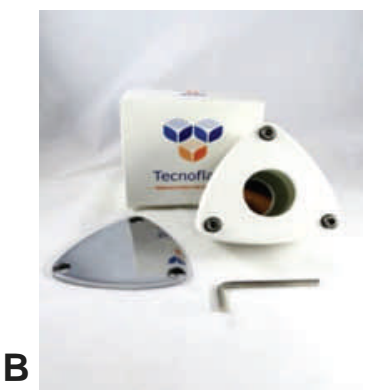

Figure (1): A- Dry pressure curing unit B- Microwave flask. 


\section{Preparations of specimens}

\section{A. Metal pattern preparation}

For each test metal patterns prepared according to the following shapes and dimensions:

1. For the transverse test metal with the dimension of $(65 \times 10 \times 3) \mathrm{mm} \pm 0.03 \mathrm{~mm}$ in length $x$ width $x$ depth, respectively (ADA no. 12, 1999)

2. For porosity test trapezoidal patterns with Dimensions of $(65 \times 62 \times 64 \times 61) \mathrm{mm}$ with $3 \mathrm{~mm}$ thickness. ${ }^{18}$

3. For water sorption and solubility test disc pattern with the dimensions of $(50 \pm 1 \mathrm{~mm}$ in diameter and $0.5 \pm 0.1 \mathrm{~mm}$ thickness), according to ADA specification No.12

4. For measuring the residual monomer of heat curing acrylic resin, metal pattern with the dimensions of $(20 \times 20 \times 3) \mathrm{mm}$ length, width, and thickness respectively. ${ }^{19}$

\section{B. Mould preparation and packing}

Dental stone mixed by ratio $19 \mathrm{ml}$ distilled water to $100 \mathrm{gr}$ stone by a vacuum mixer, poured into the lower half of dental flask on a vibrator. The metal pattern fixed by a drop of glue to a glass plate and coated with separating medium, then covered with stone to avoid trapping of air. The glass plate with the metal pattern inverted over and pressed against the stone slurry in the lower half of the flask, and remained under pressure until the stone was set. After setting, the glass plate removed and the metal pattern left uncovered and coated with separating medium. The upper half of the flask placed in position and filled with stone. Setting allowed under clamp for one hour, then the metal block removed, and separating medium applied before packing. The heat curing acrylic denture base resin mixed according to the manufacturers' instruction, the polymer/monomer ratio used for the Paladent20 was $30 \mathrm{gm} / 14 \mathrm{ml}$ while for the Major acrylic was $33 \mathrm{gm} \mathrm{/}$ $14 \mathrm{ml}$. The mixing performed for 60 seconds, the mix at dough stage; packed into the flasks.

\section{Curing:}

Each group contained seven specimens was cured by one of the following techniques:

\section{I- Water bath curing:}

The flask was placed in a water bath and remained for 1 hour in $70^{\circ} \mathrm{C}$ and then 30 minutes in $100^{\circ} \mathrm{C}$.

\section{II- Dry pressure curing:}

The heat was applied to clamped flask through the heaters in the metal plates surrounded the flask and the acrylic resin then apply pressure about 1200 lbs and $75^{\circ} \mathrm{C}$ for the temperature and cured for about 20 minutes.

\section{III- Microwave curing:}

After removal of the metal part from above the flask, the tighten flask then put in the microwave oven in $18 \%$ of 700 wattage output for 15 minutes.

\section{D-Removal of specimens:}

The cured specimens were removed from the flask after bench cooling of flasks for 15 minutes.

\section{Tests}

The tests performed for each group as follows:

\section{Transverse strength:}

The transverse deflection and transverse strength of the specimens were measured in air by three points bending on a computerized universal testing machine. The device was supplied with a central loading plunger and two supports with polished cylindrical and projection in the center of the cylindrical; the two support were apart from each by the $50 \mathrm{~mm}$ parallel to each other and perpendicular to the longitudinal central line. The force and deflection were sensed by a sensor linked directly to the computed program and record it in sequence. The test specimens were held at each end of the two supports which away from each other by $50 \mathrm{~mm}$, and the loading plunger placed midway between supports, the tests were carried out with a constant cross-head speed of $0.5 \mathrm{~mm} /$ minute.

\section{Porosity test:}

The prepared specimens were reduced in thickness from upper and lower sides with continuous water cooling; then the surface was smoothed using silicon carbide grit 
paper 240 followed by grade 400 and 600 until a very thin section $(0.4-0.5) \mathrm{mm}$ was obtained. The specimens then polished using pumice, to be examined clearly under Optical MoticDigital Microscope. Equal square fields of (5) $\mathrm{mm}$ from each specimen were made two of them at the periphery of the specimens and the other two at the center. The fields were examined under the optical microscope (at magnification 100x) to record the number of pores in each field, the mean of the pores for each specimen was calculated by dividing the total number of pores in the four fields by the number of that field.

\section{Sorption test:}

The cured disks were dried in a desiccator containing silica gel at $37^{\circ} \mathrm{C} \pm 2^{\circ} \mathrm{C}$ for 24 hours then removed to a similar analytical room temperature for 1 hour, then weighed with an analytical balance of $(0.0001 \mathrm{gm})$ accuracy. The specimens were weighed every 24 hours until a constant weight was attained, it considered as $\left(\mathrm{W}_{1}\right)$. The specimens then immersed in distilled water at $37 \pm 1^{\circ} \mathrm{C}$ inside an oven. Every 24 hours the specimens were removed from the water, wiped with a clean, dry hand towel, until free from visible moisture, waved in the air for 15 seconds, and weighed 1 minute after removal from the water and until constant weight was obtained, this represents as $\left(W_{2}\right)$. The water sorption calculated according to this equation:

Sorption $\left(\mathrm{mg} / \mathrm{cm}^{2}\right)=\mathrm{W}_{2}-\mathrm{W}_{1} / \mathrm{SA}$ (surface area of the disk)

\section{Solubility test:}

After the final weight obtained in water sorption test, the disks were reconditioned to constant weight by returning to the desiccator which containing silica gel at 37 $\pm 2^{\circ} \mathrm{C}$ as was done in previous sections, this value represents $\left(W_{3}\right)$. The soluble matter lost during immersion was determined to the nearest $0.01 \mathrm{mg} / \mathrm{cm}^{2}$. The water sorption was calculated according to the following equation:

Solubility $\left(\mathrm{mg} / \mathrm{cm}^{2}\right)=W_{1}-W_{3} l$ SA (surface area of the disk)

\section{Residual monomer:}

HPLC was used to quantify the residual methyl methacrylate (MMA) content in the sample of heat-cure and self-cure material. A sample of $50 \mathrm{mg}$ was dissolved in $1 \mathrm{ml}$ of acetone and then $10 \mathrm{ml}$ of methanol was added to the solution to precipitate the polymer. The supernatant of the solution was filtered through a $0.45 \mu \mathrm{m}$ pore Millipore filter. HPLC analysis was performed using LC-2010C Shimadzu Japan system equipped with a CAPCELL PAK C18 column. Ten $\mathrm{ml}$ of the sample solution was injected and analyzed at $40^{\circ} \mathrm{C}$ at a flow rate of $1.0 \mathrm{ml} / \mathrm{min}$ with acetonitrile water (50/50). ${ }^{22}$

\section{Statistical analysis:}

All data were expressed in means \pm standard deviation. The statistical analysis was carried out using the statistical package for the social sciences (version 19). One-way analysis of variance (ANOVA) was used to compare between means of groups. Least Significant Difference (LSD) was used to compare between each two specific means within the list of means analyzed by ANOVA. A $P$ value of $\leq 0.05$ was considered statistically significant. 


\section{Results}

Transverse strength test: The results of

Table 1: Descriptive statistics, LSD test, mean value, SD and ANOVA for the Transverse strength test.

\begin{tabular}{|c|c|c|c|c|c|c|}
\hline Six groups & Six groups & $P$ value & SIG & $\begin{array}{c}\text { Mean } \\
\left(\mathrm{N} / \mathrm{mm}^{2}\right)\end{array}$ & SD & $\begin{array}{c}P \\
\text { (ANOVA) }\end{array}$ \\
\hline \multirow[t]{5}{*}{ Conventional-pal } & pressure-pal & $<0.001$ & $\mathrm{HS}$ & 256.20 & 30.498 & \\
\hline & Microwave-pal & $<0.001$ & HS & & & \\
\hline & Conventional-major & 0.020 & HS & & & \\
\hline & pressure-major & 0.137 & NS & & & \\
\hline & Microwave-major & 0.041 & HS & & & \\
\hline \multirow[t]{5}{*}{ pressure-pal } & Conventional-pal & $<0.001$ & HS & 171.50 & 12.973 & \\
\hline & Microwave-pal & 0.148 & NS & & & \\
\hline & Conventional-major & $<0.001$ & $\mathrm{HS}$ & & & \\
\hline & pressure-major & $<0.001$ & $\mathrm{HS}$ & & & \\
\hline & Microwave-major & $<0.001$ & $\mathrm{HS}$ & & & \\
\hline \multirow[t]{5}{*}{ Microwave-pal } & Conventional-pal & $<0.001$ & $\mathrm{HS}$ & 188.96 & 8.249 & \\
\hline & pressure-pal & 0.148 & NS & & & \\
\hline & Conventional-major & 0.003 & HS & & & \\
\hline & pressure-major & $<0.001$ & $\mathrm{HS}$ & & & \\
\hline & Microwave-major & $<0.001$ & $\mathrm{HS}$ & & & \\
\hline \multirow[t]{5}{*}{ Conventional-major } & Conventional-pal & 0.020 & HS & 227.31 & 21.543 & $<0.001$ \\
\hline & pressure-pal & $<0.001$ & HS & & & \\
\hline & Microwave-pal & 0.003 & HS & & & \\
\hline & pressure-major & 0.361 & NS & & & \\
\hline & Microwave-major & $<0.001$ & HS & & & \\
\hline \multirow[t]{5}{*}{ pressure-major } & Conventional-pal & 0.137 & NS & 238.24 & 29.869 & \\
\hline & pressure-pal & $<0.001$ & $\mathrm{HS}$ & & & \\
\hline & Microwave-pal & $<0.001$ & $\mathrm{HS}$ & & & \\
\hline & Conventional-major & 0.361 & NS & & & \\
\hline & Microwave-major & 0.001 & HS & & & \\
\hline \multirow[t]{5}{*}{ Microwave-major } & Conventional-pal & 0.041 & HS & 281.23 & 20.206 & \\
\hline & pressure-pal & $<0.001$ & $\mathrm{HS}$ & & & \\
\hline & Microwave-pal & $<0.001$ & $\mathrm{HS}$ & & & \\
\hline & Conventional-major & $<0.001$ & $\mathrm{HS}$ & & & \\
\hline & pressure-major & 0.001 & $\mathrm{HS}$ & & & \\
\hline Total & & & & 227.24 & 43.256 & \\
\hline
\end{tabular}


2. Porosity test: The results porosity test for Paladent20 and Major acrylic resins and the result of LSD test shown in Table 2 that there was no statistical significance difference present in only two comparisons, between pressurePaladent20, pressure-Major, microwavePaladent20 and microwave-Major.

Table 2: Descriptive statistics, LSD test, mean value, SD and ANOVA for porosity test.

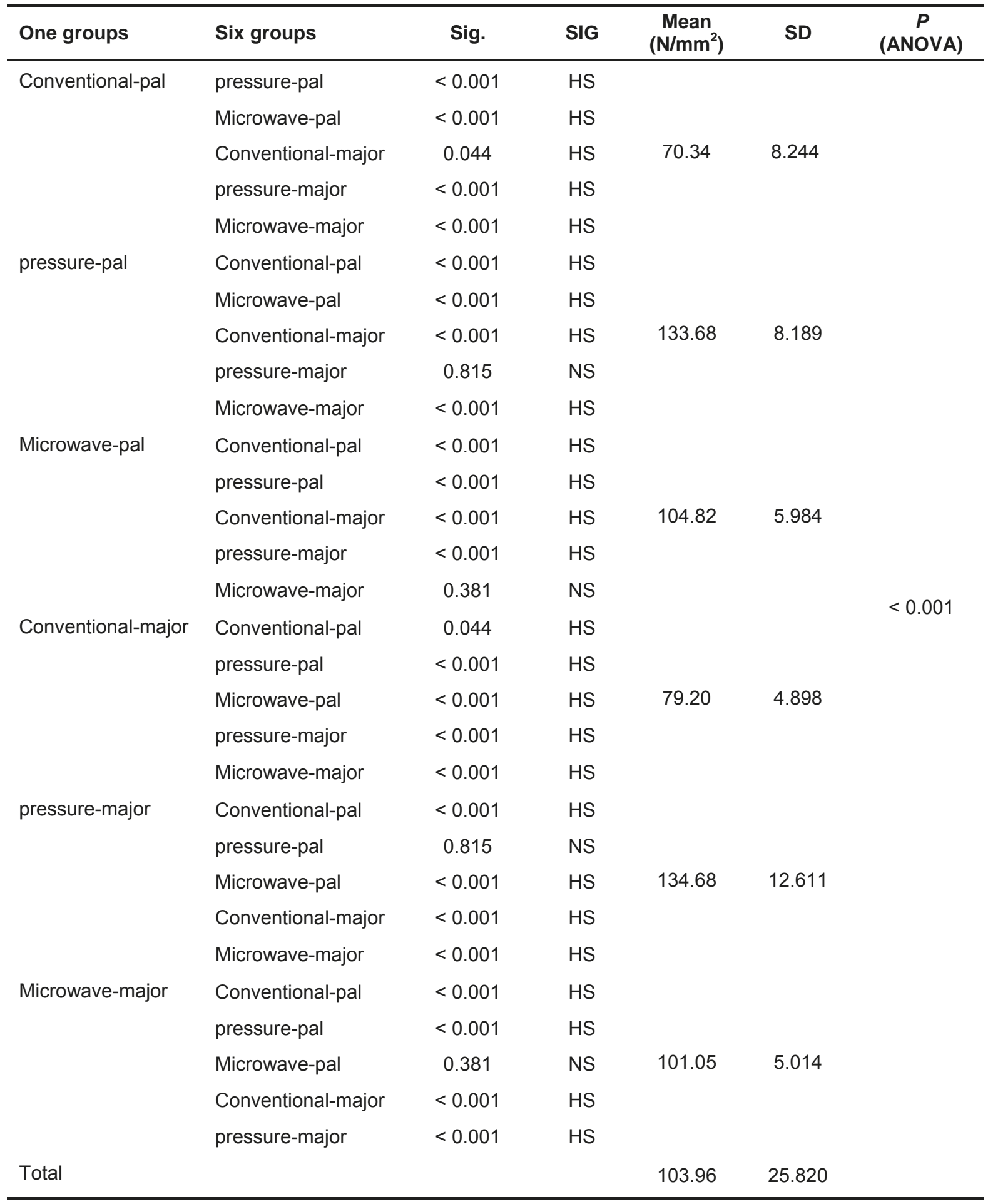


3. Water sorption: The results of water ANOVA result are shown in Table 3. sorption test with LSD test and

Table 3: Descriptive statistics, LSD test, mean value, SD and ANOVA for water sorption test.

\begin{tabular}{|c|c|c|c|c|c|c|c|}
\hline $\begin{array}{l}\text { Dependent } \\
\text { Variable }\end{array}$ & Six groups & five groups & $\begin{array}{c}P \\
\text { (VALUE) }\end{array}$ & SIG & Mean & SD & $\begin{array}{c}P \\
\text { (ANOVA) }\end{array}$ \\
\hline \multirow[t]{30}{*}{ Water_sorption } & Conventional-pal & pressure-pal & 0.404 & NS & & & \\
\hline & & Microwave-pal & $<0.001$ & HS & & & \\
\hline & & Conventional-major & 0.861 & NS & 0.63 & 0.157 & \\
\hline & & pressure-major & 0.003 & HS & & & \\
\hline & & Microwave-major & 0.012 & HS & & & \\
\hline & pressure-pal & Conventional-pal & 0.404 & NS & & & \\
\hline & & Microwave-pal & $<0.001$ & HS & & & \\
\hline & & Conventional-major & 0.508 & NS & 0.69 & 0.071 & \\
\hline & & pressure-major & 0.024 & HS & & & \\
\hline & & Microwave-major & 0.082 & NS & & & \\
\hline & Microwave-pal & Conventional-pal & $<0.001$ & HS & & & \\
\hline & & pressure-pal & $<0.001$ & HS & & & \\
\hline & & Conventional-major & $<0.001$ & HS & 0.98 & 0.140 & \\
\hline & & pressure-major & 0.112 & NS & & & \\
\hline & & Microwave-major & 0.034 & HS & & & \\
\hline & Conventional-major & Conventional-pal & 0.861 & NS & & & $<0.001$ \\
\hline & & pressure-pal & 0.508 & NS & & & \\
\hline & & Microwave-pal & $<0.001$ & HS & 0.64 & 0.093 & \\
\hline & & pressure-major & 0.005 & HS & & & \\
\hline & & Microwave-major & 0.019 & HS & & & \\
\hline & pressure-major & Conventional-pal & 0.003 & HS & & & \\
\hline & & pressure-pal & 0.024 & HS & & & \\
\hline & & Microwave-pal & 0.112 & NS & 0.86 & 0.145 & \\
\hline & & Conventional-major & 0.005 & HS & & & \\
\hline & & Microwave-major & 0.572 & NS & & & \\
\hline & Microwave-major & Conventional-pal & 0.012 & HS & & & \\
\hline & & pressure-pal & 0.082 & NS & & & \\
\hline & & Microwave-pal & 0.034 & $\mathrm{HS}$ & 0.82 & 0.177 & \\
\hline & & Conventional-major & 0.019 & $\mathrm{HS}$ & & & \\
\hline & & pressure-major & 0.572 & NS & & & \\
\hline
\end{tabular}


4. Water solubility: The results of water ANOVA result are shown in Table 4. solubility test with LSD test and

Table 4: Descriptive statistics, LSD test, mean value, SD and ANOVA for water solubility test.

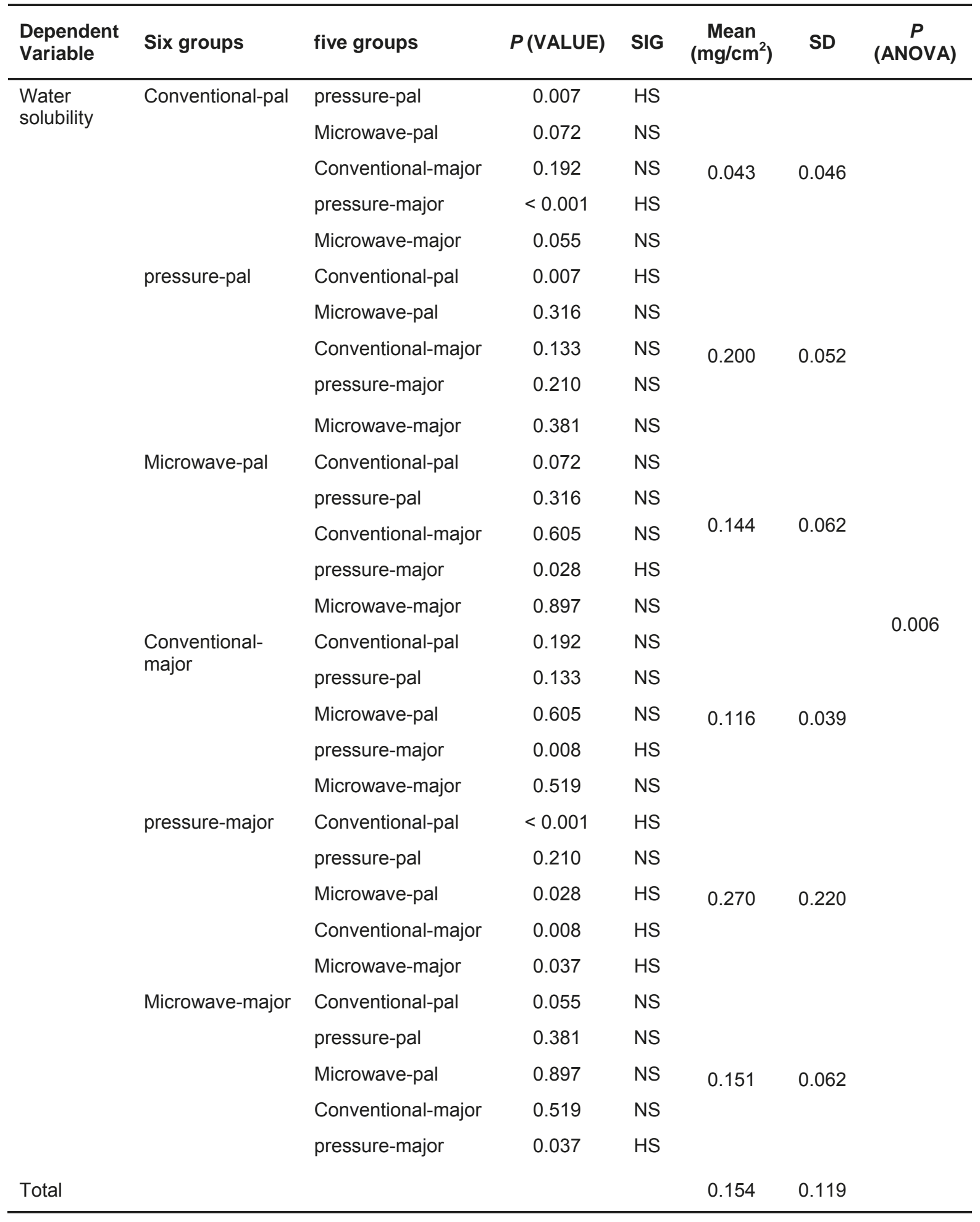


5. Residual monomer: The results of that all the groups have highly statistical residual monomer levels in Paladent 20 and Major acrylic resins, LSD test and ANOVA shown in Table 5 revealed significance among all the group and only (conventional-Paladent20 and conventional -Major) not statistical significance.

Table 5: Descriptive statistics, LSD test, mean value, SD and ANOVA for residual monomer test.

\begin{tabular}{|c|c|c|c|c|c|c|}
\hline Group & 6 Groups & $P$ (VALUE) & SIG & $\begin{array}{c}\text { Mean } \\
\left(\mathrm{mg} / \mathrm{cm}^{2}\right)\end{array}$ & SD & $P$ (ANOVA) \\
\hline \multirow[t]{5}{*}{ Conv_paladent20 } & Pressure_paladent20 & .000 & $\mathrm{HS}$ & & & \\
\hline & Micro_paladent20 & .000 & HS & & & \\
\hline & Conv_Major & .789 & NS & 0.551 & 0.010 & \\
\hline & Pressure_Major & .000 & HS & & & \\
\hline & Micro_Major & .000 & HS & & & \\
\hline \multirow[t]{5}{*}{ Pressure_paladent20 } & Conv_paladent20 & .000 & HS & & & \\
\hline & Micro_paladent20 & .000 & HS & & & \\
\hline & Conv_Major & .000 & $\mathrm{HS}$ & 0.344 & 0.011 & \\
\hline & Pressure_Major & .000 & HS & & & \\
\hline & Micro_Major & .012 & HS & & & \\
\hline \multirow[t]{5}{*}{ Micro_paladent20 } & Conv_paladent20 & .000 & $\mathrm{HS}$ & & & \\
\hline & Pressure_paladent20 & .000 & $\mathrm{HS}$ & & & \\
\hline & Conv_Major & .000 & HS & 0.732 & 0.241 & \\
\hline & Pressure_Major & .000 & $\mathrm{HS}$ & & & \\
\hline & Micro_Major & .000 & HS & & & \\
\hline \multirow[t]{5}{*}{ Conv_Major } & Conv_paladent20 & .789 & NS & & & $<0.001$ \\
\hline & Pressure_paladent20 & .000 & HS & & & \\
\hline & Micro_paladent20 & .000 & HS & 0.565 & 0.012 & \\
\hline & Pressure_Major & .000 & HS & & & \\
\hline & Micro_Major & .000 & HS & & & \\
\hline \multirow[t]{5}{*}{ Pressure_Major } & Conv_paladent20 & .000 & HS & & & \\
\hline & Pressure_paladent20 & .000 & HS & & & \\
\hline & Micro_paladent20 & .000 & $\mathrm{HS}$ & 0.844 & 0.007 & \\
\hline & Conv_Major & .000 & HS & & & \\
\hline & Micro_Major & .000 & $\mathrm{HS}$ & & & \\
\hline \multirow[t]{5}{*}{ Micro_Major } & Conv_paladent20 & .000 & $\mathrm{HS}$ & & & \\
\hline & Pressure_paladent20 & .012 & HS & & & \\
\hline & Micro_paladent20 & .000 & $\mathrm{HS}$ & 0.484 & 0.019 & \\
\hline & Conv_Major & .000 & HS & & & \\
\hline & Pressure_Major & .000 & HS & & & \\
\hline Total & & & & 0.586 & 0.013 & \\
\hline
\end{tabular}




\section{Discussion}

The microwave irradiation for Major acrylic resin showed the mean value of transverse strength more than the microwave irradiation for the Paladent20 that showed the lowest mean value. This may refer to the difference in the chemical structure between the two materials and free radical polymerization reaction does not result in complete conversion of all carbon-carbon double bonds of Major acrylic, therefore, acrylic resins known to contain and release unpolymerized monomers. The highest mean value of porosity produced by dry heat pressure curing for both acrylic resins may be due to the type of heat transmission during curing. The flask first heated, transmitted to the investment and then the acrylic dough gets heated so that the time may be used for curing not the correct time until heating reaches to the polymer and it affects the polymerization. The heat used in this technique was applied to the upper and lower surfaces, not like the microwave and conventional which heated in all area so that may be the heating for the polymerization not equal in every direction. Conventional curing technique, compared with the microwave technique produced lowest mean value for the water sorption. The increased water sorption in microwave irradiation may be due to faster curing of the resin compared to the conventional water bath, and degree of curing increased a little. Microwaves act only on the monomer, which decreases in the same proportion as polymerization increases. Microwave causes the monomer molecules within the acrylic to orient themselves in an electromagnetic field, numerous polarized molecules are flipped over rapidly and generate heat due to molecular friction. Initiating radicals then able to react with monomers to start polymerization. Microwave processing temperatures beyond $100.3^{\circ} \mathrm{C}$ caused vaporization of the monomer and produced porosity, voids in the structure of cured resin increase water sorption. ${ }^{5,20,21}$ The lowest mean value for solubility in conventional curing when compared with microwave irradiation can be explained by that the acrylic resin cured by microwave ovens polymerized by microwave energy released the least residual monomer, due to internal boiling of the acrylic monomer. One of the soluble materials present in acrylic resins is a free monomer. So when more residual monomer present more solubility will be present. The lowest residual monomer appeared in dry heat pressure curing for Paladent20 acrylic resin when compared with the other techniques. This may be due to the high temperature was reached within the specimens make the polymerization proceeds to a high conversion and low level of residual monomer was detected.

\section{Conclusion}

The new technique pressure heat curing of Paladent 20 produced some improvement of properties by lower water sorption and lower level of residual monomer, while it produced higher porosity, more water sorption, and less resistance to bending. This technique of curing of Major acrylic resin induced more porosity, higher bending strength, water sorption and solubility. The level of residual monomer was lowered in both brands when cured by pressure heat curing. All properties of Major acrylic denture base resin were lower when cured by the conventional method. Microwave irradiation of Paladent 20 showed the higher values of most of the properties, except the bending strength and water sorption showed lower values. Microwave irradiation curing of Major acrylic denture base induced more porosity, higher bending strength, and water solubility, while the water sorption and residual monomer level were decreased.

\section{Conflicts of interest}

The authors report no conflicts of interest.

\section{References}

1. Craig R, Powers J. Restorative Dental materials. $11^{\text {th }}$ ed. St Louis; 2002. P. 635-89. 
2. Craig RG .Restorative Dental Materials. Philadelphia, Pa: Saunders; 1993. P. 478.

3. Rahal JS, Mesquita MF, Henriques GE, Nobilo MA. Surface roughness of acrylic resins submitted to mechanical and chemical polishing. J Oral Rehabil 2004; 31:1075-9.

4. Phoenix RD. Denture base resins. In: Anusavice K. Phillips' science of dental materials. $11^{\text {th }}$ ed. China: Saunders Elsevier; 2003. P. 721-57.

5. Vallittu PK, Ruyter IE, Buykuilmaz S. Effect of polymerization temperature and time on the residual monomer content of denture base polymers.Eur J Oral Sci 1998; 106:588-93.

6. Compagnoni MA, Barbosa DB, de Souza RF, Pero AC. The effect of polymerization cycles on porosity of microwave-processed denture base resin. J Prosthet Dent 2004; 91(3): 281-5.

7. Schneider RL, Curtis ER, Clancy JMS. Tensile bond strength of acrylic resin denture teeth to a microwave- or heat-processed denture base.J Prosthet Dent 2002; 88: 145-50.

8. Schibayama R, GennariFilho H, Mazaro JVK, Vedovatto E, Assunclo WG. Effect of flasking and polymerization techniques on tooth movement in complete denture processing. J Prosthodont 2009; 18(3): 250-64.

9. Arora S, Khindria S, Garg S, Mittal S. Comparative Evaluation of Linear Dimensional Changes of Four Commercially Available Heat Cure Acrylic Resins. Indian J Dent Sci 2011; 4(3): 133-80.

10. Unalan F, Dikbas I, Gurbuz O. Transverse strength of polymethylmethacryltate reinforced with different forms and concentrations of E-glass fibers. OHDMBSC 2010; IX (3):134-76.

11. Pero AC, Marra J, Paleari AG, de Souza RF, Ruvolo-Filho A, Compagnoni MA. Reliability of a method for evaluating porosity in denture base resins. Gerodontology 2011; 28(2):127-33.

12. Anusavice K. Philip's science of dental materials. $11^{\text {th }}$ ed. Philadlphia: WB Sauders; 1996. P.143-69

13. Takashi A, Hiroshi M, Taizo $H$. Properties of highly cross-linked autopolymerizing reline acrylic resins. J Prosthet Dent 1995; 73: 55-9.

14. Al-Nori, Ali AA, Rajab LT. Water sorption of heat-cured acrylic resin.Al-Rafidain Dent J 2007; 7(2): 186-94

15. Jorge JH, Giampaolo ET, Machado AL, Vergani CE. Cytotoxicity of denture base acrylic resin. J Appl Oral Sci 2003; 14(3):190-3.

16. Dogan A, Bek B, Cevik N, Usanmaz A. The effect of preparation conditions of acrylic denture base materials on the level of residual monomer, mechanical properties and water absorption. J Dent 1995; 23: 313-8.

17. Harrison A, Huggett R. Effect of the curing cycle on residual monomer levels of acrylic resin denture base polymers.J Dent 1992; 20:370-4.

18. Habib SH. The effect of microwave postpoymerization treatment on some properties of cold cured and visible light-cured acrylic resin materials. M. Sc. Thesis, College of Dentistry,
Hawler Medical University; 2011.

19. Hassan AL-Bahar ZJ. Evaluation the Effect of Incorporated Hydroxyapatite Prepared from Dried Egg Shell on Some Properties of Relined Denture Base. M.Sc thesis, Mosul University; 2011.

20. John C, Eugene P. Porosity reduction and its associated effect on the diametral tensile strength of activated acrylic resins. J Prosthet Dent 1985; 53(3): 374-9.

21. Lai CP, Tsaia MH, Chena M, Chang HS, Tayb HH.Morphology and properties of denture acrylic resins cured by microwave energy and conventional water bath. Dent Mater 2004; 20: 133-41.

22. Mohamed SH, Al-JadiAM, Ajaal T. Using of HPLC Analysis for Evaluation of Residual Monomer Content in Denture Base Material and Their Effect on Mechanical Properties. Journal of Physical Science 2008; 19(2): 127-35. 